\title{
Numerical simulation analysis of the induced thrust on a char particle in reaction process
}

\author{
Shengyu Zhou ${ }^{1}$, Zhongjie Shen ${ }^{2}$, Qinfeng Liang ${ }^{2}$, Jian-Liang $\mathrm{Xu}^{1}$, Zheng-Hua $\mathrm{Dai}^{1}$, and \\ Haifeng Liu ${ }^{1}$
}

${ }^{1}$ Affiliation not available

${ }^{2}$ East China University of Science and Technology

July 20, 2021

\begin{abstract}
The force exerted on particles is of great significance to the flow and reaction characteristics of particles in gasifier. In this study, the unbalanced thrust, especially its magnitude, of a single char particle induced by chemical reactions during combustion process is investigated numerically, based on the random distribution of active sites. It is revealed that the nonuniform distribution of active sites directly leads to the nonuniform release of gaseous products, which accounts for the net induced thrust of particles. The effects of active site ratio, ambient gas temperature and particle diameter on the induced thrust of reaction particle were investigated. The results show that the induced thrust on particles could be equal to the magnitude of particle gravity. The induced thrust decreases with the increase of active area and particle diameter. And it is enhanced with the increase of ambient temperature.
\end{abstract}

\section{Hosted file}

Manuscript.docx available at https://authorea.com/users/426664/articles/531108-numericalsimulation-analysis-of-the-induced-thrust-on-a-char-particle-in-reaction-process 